care and office based chest medicine clinics. A convenience sample of 500 was selected.

Results We report the characteristics of the first 250 COPD patients from our ongoing 500 patient survey.

Basic demographics 55\% Male, 45\% Female. Mean age patients $68 \pm 12$ yrs, all patients were previous smokers with $56 \pm 10$ pkt/yrs smoking history. 34\% remain current smokers.

Mean FEV1 48\% \pm 10\%, Mean FEV1/FVC ratio 49\% \pm 10 . Median mMRC dyspnea score 2. Mean CAT score $18 \pm 10$ (Range 0-38).

GOLD Stage Classification 13\% GOLD Stage A, 67\% GOLD Stage B, 1\% GOLD Stage C and 19\% GOLD Stage D.

Current treatment LAMA (long-acting muscarinic antagonist) was prescribed to over $90 \%$ of all patients in groups $\mathrm{B}, \mathrm{C}$ and $\mathrm{D}$ whereas monotherapy with LABA (long acting beta-agonist) or dual bronchodilation with LABA/LAMA therapy was prescribed to less than $5 \%$.

There was significant overtreatment with ICS/LABA in all categories with high dose ICS (inhaled corticosteroid) being preferred.

$20 \%$ of patients in GOLD Stage A where receiving Triple therapy (LAMA + ICS/LABA) and a further 20\% where receiving monotherapy with ICS/LABA, yet had no history of exacerbations.

$30 \%$ of patients in GOLD Stage B where receiving Triple therapy (LAMA + ICS/LABA) yet had no history of exacerbations. Conclusion Current Canadian Guidelines and the GOLD strategy focus on symptom relief and striving to prevent exacerbations with step-wise prescription of short and long-acting bronchodilators with individual or combinations of LAMA, LABA, LAMA/LABA or ICS/LABA inhalers. Patients in GOLD Group $C$ are rare. Current prescription choices in our survey does not reflect current evidence or guidelines. We report a heavy reliance on ICS/LABA along with over prescription of triple therapy at all stages of disease.

\section{P253 META - ANALYSIS ON STATINS IN CHRONIC OBSTRUCTIVE PULMONARY DISEASE}

Gplc Ambrocio, IA Roque, II MPPC Jorge. Section of Pulmonary Medicine, Department of Medicine, University of the Philippines - Philippine General Hospital, Manila, Philippines

\subsection{6/thoraxjnl-2014-206260.381}

Background Chronic obstructive pulmonary disease (COPD) is an inflammatory lung disease characterised by progressive airflow limitation. Statins have anti-inflammatory and immunomodulating properties that could alter inflammation of the airways. The objective of this study is to systematically evaluate the effectiveness of adjunct statin therapy in improving exercise tolerance and pulmonary function indices in patients with chronic obstructive pulmonary disease.

Search strategy and inclusion criteria A thorough search was done using Medline and PubMed, with limits set on studies involving humans in a randomised control trial in English that examined the effect of statins in COPD.

Study manoeuvres All the articles retrieved were appraised separately and independently by two reviewers for its applicability, validity and the methodological quality of the randomised control trials by assessing allocation, blinding, and if follow up rate was adequate. Disagreements between the reviewers were resolved by consensus.

Statistical analysis Data collected were analysed using Review Manager Version 5.2.
Results A total of two articles met the end criteria. Outcome shows improvement in exercise time (treadmill test) at 95\% CI, with statistically significant benefit with mean difference of 335.18 [253.93, 416.43] favouring Pravastatin group. The studies show inconclusive results for Pravastatin in improving FEV1 (\%) with 95\% CI with mean difference of 0.05 [-4.61, 4.7]. The outcome in total lung capacity shows inconclusive results but shows a trend toward benefit with $95 \%$ CI with mean difference of $-0.08[-0.46,0.30]$. Inspiratory capacity results at 95\% CI with mean difference of 0.13 [-0.06, 0.32] showed an inconclusive outcome but has a trend toward benefit. Improvement in the Borg dyspnea score at 95\% CI, showing statistically significant benefit with mean difference of -2.91 [-3.19, -2.63] favouring the Pravastatin group.

Conclusions Statins already have an established role in treating cardiovascular patients because of their cholesterol-lowering ability, but also have anti-inflammatory and immunomodulatory effects that are beneficial in airway inflammation in COPD. Statin administration to COPD patients showed amelioration in exercise tolerance, improvement in dyspnea scores and augmentation in pulmonary function indices. Thus, statins may be useful as adjunct to currently available therapies as well as improvement in lipid status.

\section{P254 ONCE-DAILY TIOTROPIUM AND OLODATEROL FIXED- DOSE COMBINATION VIA THE RESPIMAT® IMPROVES OUTCOMES VERSUS MONO-COMPONENTS IN COPD IN TWO 1-YEAR STUDIES}

${ }^{1} \mathrm{R}$ Buhl, ${ }^{2} \mathrm{E}$ Derom, ${ }^{3} \mathrm{G}$ Ferguson, ${ }^{4} \mathrm{E}$ Pizzichini, ${ }^{5} \mathrm{~J}$ Reid, ${ }^{6} \mathrm{H}$ Watz, ${ }^{7} \mathrm{~L}$ Grönke, ${ }^{8} \mathrm{~A}$ Hamilton, ${ }^{7} \mathrm{~K}$ Tetzlaff, ${ }^{9} \mathrm{~L}$ Korducki, ${ }^{10} \mathrm{H}$ Huisman, ${ }^{10} \mathrm{~S}$ Waitere-Wijker, ${ }^{11} \mathrm{~F}$ Maltais. ${ }^{1}$ Pulmonary Department, Mainz University Hospital, Mainz, Germany; ${ }^{2}$ Ghent University Hospital, Ghent, Belgium; ${ }^{3}$ Pulmonary Research Institute of Southeast Michigan, Livonia, Michigan, USA; ${ }^{4}$ NUPAIVA (Asthma Research Centre), Universidade Federal de Santa Catarina, Santa Catarina, Brazil; ${ }^{5}$ Dunedin School of Medicine, University of Otago, Dunedin, New Zealand; ${ }^{6}$ Pulmonary Research Institute at Lung Clinic Grosshansdorf, Airway Research Center North, Member of the German Center for Lung Research, Grosshansdorf, Germany; ${ }^{7}$ Boehringer Ingelheim Pharma GmbH and Co. KG, Ingelheim, Germany; ${ }^{8}$ Boehringer Ingelheim, Burlington, Ontario, Canada; ${ }^{9}$ Boehringer Ingelheim Pharmaceuticals Inc., Ridgefield, Connecticut, USA; ${ }^{10}$ Boehringer Ingelheim B. V., Alkmaar, The Netherlands; ${ }^{11}$ Centre de Recherche, Institut Universitaire de Cardiologie Et de Pneumologie de Québec, Québec, Canada

10.1136/thoraxjnl-2014-206260.382

Introduction Tiotropium (T), a once-daily long-acting muscarinic antagonist, is a well-established first-line maintenance treatment in chronic obstructive pulmonary disease (COPD); olodaterol $(\mathrm{O})$ is a once-daily long-acting $\beta_{2}$-agonist that has recently gained approval in several countries. Two Phase III replicate pivotal studies assessed the efficacy and safety of fixeddose combinations of $\mathrm{T}$ and $\mathrm{O}(\mathrm{T}+\mathrm{O})$ delivered via Respimat ${ }^{\circledR}$ Soft Mist ${ }^{\mathrm{TM}}$ inhaler in patients with GOLD 2-4 COPD.

Methods Two 52-week, double-blind, parallel-group studies randomised 5162 patients to O $5 \mu \mathrm{g}$, T $2.5 \mu \mathrm{g}$, T $5 \mu \mathrm{g}$, T+O 2.5/5 $\mu \mathrm{g}$ or $\mathrm{T}+\mathrm{O} 5 / 5 \mu \mathrm{g}$. Primary efficacy end points were trough forced expiratory volume in 1 second $\left(\mathrm{FEV}_{1}\right)$ response (ie change from baseline), $\mathrm{FEV}_{1}$ area under the curve from $0-3 \mathrm{~h}$ and St George's Respiratory Questionnaire (SGRQ) total score after 24 weeks. Pooled data from the two studies are presented here; lung function from the individual studies will subsequently be provided.

Results All treatments resulted in clinically relevant improvements in lung function, with significant increases with both $\mathrm{T}$ $+\mathrm{O}$ doses over the individual components ( $\mathrm{p} 1$ responses were $0.055 \mathrm{~L}(\mathrm{O} 5 \mu \mathrm{g}), 0.073 \mathrm{~L}(\mathrm{~T} 2.5 \mu \mathrm{g}), 0.080 \mathrm{~L}$ (T $5 \mu \mathrm{g}), 0.118$ 
$\mathrm{L}(\mathrm{T}+\mathrm{O} 2.5 / 5 \mu \mathrm{g})$ and $0.140 \mathrm{~L}(\mathrm{~T}+\mathrm{O} 5 / 5 \mu \mathrm{g})$. SGRQ total scores improved by 5.1 (O $5 \mu \mathrm{g}), 5.7$ (T $2.5 \mu \mathrm{g}), 5.6$ (T $5 \mu \mathrm{g})$, $6.2(\mathrm{~T}+\mathrm{O} 2.5 / 5 \mu \mathrm{g})$ and 6.8 points $(\mathrm{T}+\mathrm{O} 5 / 5 \mu \mathrm{g})$; differences between $\mathrm{T}+\mathrm{O} 5 / 5 \mu \mathrm{g}$ and $\mathrm{O} 5 \mu \mathrm{g}$ and $\mathrm{T} 5 \mu \mathrm{g}$ were statistically significant $(\mathrm{p}$

Conclusions $\mathrm{T}+\mathrm{O} 5 / 5 \mu \mathrm{g}$ significantly improved lung function and provided symptomatic benefit over O $5 \mu \mathrm{g}$ and $\mathrm{T} 5 \mu \mathrm{g}$.

\section{P255 ONCE-DAILY TIOTROPIUM RESPIMAT $®$ ADD-ON TO AT LEAST ICS MAINTENANCE THERAPY REDUCES EXACERBATION RISK IN PATIENTS WITH UNCONTROLLED SYMPTOMATIC ASTHMA}

${ }^{1}$ DMG Halpin, ${ }^{2} \mathrm{P}$ Paggiaro, ${ }^{3} \mathrm{E}$ Bleecker, ${ }^{4} \mathrm{M}$ Engel, ${ }^{4} \mathrm{P}$ Moroni-Zentgraf, ${ }^{4} \mathrm{H}$ Schmidt, ${ }^{5} \mathrm{HAM}$ Kerstjens. 'Royal Devon and Exeter Hospital, Exeter, UK; ${ }^{2}$ University of Pisa, Pisa, Italy; ${ }^{3}$ Center for Genomics and Personalized Medicine, Wake Forest School of Medicine, Winston-Salem, USA; ${ }^{4}$ Boehringer Ingelheim Pharma GmbH and Co. KG, Biberach an Der Riss, Germany; ${ }^{5}$ University Medical Center Groningen, University of Groningen, Groningen, The Netherlands

\subsection{6/thoraxjnl-2014-206260.383}

Background A reduction in asthma exacerbation risk may provide improvements in clinical burden, patient experience and healthcare costs. In Phase III trials, once-daily tiotropium (delivered via the Respimat ${ }^{\circledR}$ SoftMist ${ }^{\mathrm{TM}}$ inhaler) added on to at least inhaled corticosteroids (ICS) improved lung function in patients with symptomatic asthma. We investigated exacerbation risk in each trial.

Methods Five Phase III, double-blind, placebo-controlled, parallel-group trials in patients with symptomatic asthma. Patients received tiotropium Respimat ${ }^{\circledR} 5 \mu$ g or placebo as add-on to at least ICS maintenance therapy (Table). Pre-planned co-primary or secondary end points were time to first severe exacerbation and time to any asthma worsening.

Results Mean baseline \% of predicted forced expiratory volume in 1 second, seven-question Asthma Control Questionnaire score and ICS dose $(\mu \mathrm{g})$ were: $56.0 \pm 13.1,2.6 \pm 0.7,1198 \pm 539$ (PrimoTinA-asthma $\left.{ }^{\circledR}\right) ; 75.1 \pm 11.5,2.2 \pm 0.5,660 \pm 213$ (MezzoTinAasthma $\left.{ }^{\circledR}\right) ; 77.7 \pm 11.9,2.1 \pm 0.4,381 \pm 78$ (GraziaTinAasthma ${ }^{\circledR}$ ). Tiotropium Respimat ${ }^{\circledR} 5 \mu \mathrm{g}$ reduced severe asthma exacerbation risk by at least $21 \%$ in all three severity cohorts (Table) and asthma worsening risk versus placebo in all trials, with a statistically significant reduction in the PrimoTinA-asthma ${ }^{\circledR}$ trial.

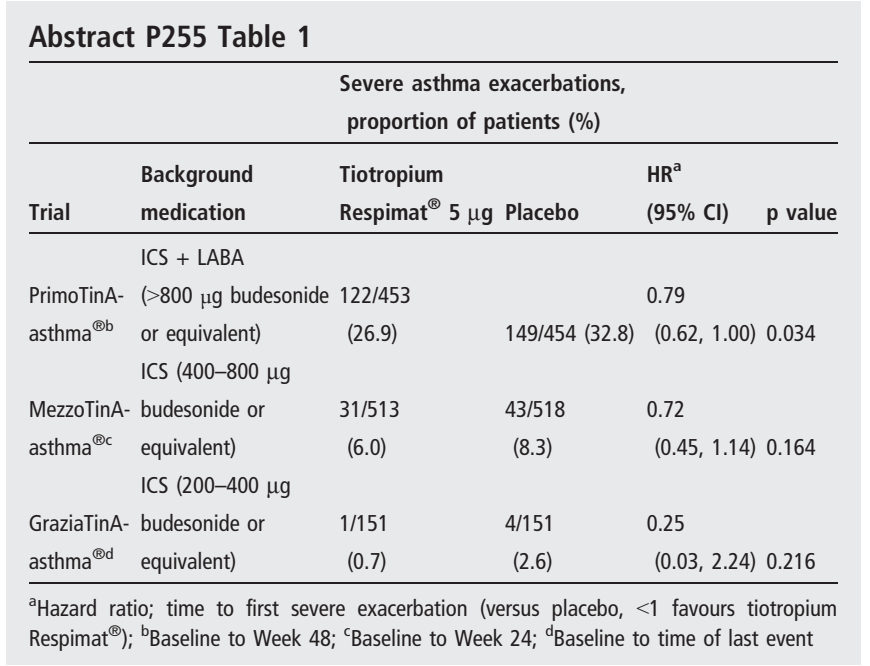

Conclusion Once-daily tiotropium Respimat ${ }^{\circledR} 5 \mu \mathrm{g}$ add-on to at least ICS maintenance therapy consistently reduced exacerbations across asthma severities and so may be a beneficial add-on option to reduce current and future exacerbation risk.

\section{P256 SAFETY OF ONCE-DAILY TIOTROPIUM AND OLODATEROL FIXED-DOSE COMBINATION VIA THE RESPIMAT IN CHRONIC OBSTRUCTIVE PULMONARY DISEASE IN TWO 1-YEAR STUDIES}

${ }^{1} \mathrm{R}$ Buhl, ${ }^{2} \mathrm{R}$ Abrahams, ${ }^{3} \mathrm{~L}$ Bjermer, ${ }^{4} \mathrm{E}$ Derom, ${ }^{5} \mathrm{M}$ Fležar, ${ }^{6} \mathrm{~J}$ Hébert, ${ }^{7} \mathrm{~A}$ Veale, ${ }^{8} \mathrm{~L}$ Grönke, ${ }^{9} \mathrm{~A}$ Hamilton, ${ }^{8} \mathrm{~K}$ Tetzlaff, ${ }^{10} \mathrm{~L}$ Korducki, ${ }^{11} \mathrm{H}$ Huisman, ${ }^{11} \mathrm{~S}$ Waitere-Wijker, ${ }^{12} \mathrm{~L} \mathrm{McG}$ arvey. ${ }^{1}$ Pulmonary Department, Mainz University Hospital, Mainz, Germany; ${ }^{2}$ Morgantown Pulmonary Associates, Morgantown, West Virginia, USA; ${ }^{3}$ Department of Respiratory Medicine and Allergology, Lund University, Lund, Sweden; ${ }^{4}$ Ghent University Hospital, Ghent, Belgium; ${ }^{5}$ Klinika Golnik, Golnik, Slovenia; ${ }^{6}$ Centre de Recherche Appliquée en Allergie de Québec (CRAAQ), Québec, Canada; 'Department of Respiratory Medicine, The Queen Elizabeth Hospital, Adelaide, Australia; ${ }^{8}$ Boehringer Ingelheim Pharma GmbH and Co. KG, Ingelheim, Germany; ${ }^{9}$ Boehringer Ingelheim, Burlington, Ontario, Canada; ${ }^{10}$ Boehringer Ingelheim Pharmaceuticals Inc., Ridgefield, Connecticut, USA; ${ }^{11}$ Boehringer Ingelheim B. V., Alkmaar, The Netherlands; ${ }^{12}$ Centre for Infection and Immunity, School of Medicine, Dentistry and Biomedical Sciences, Queen's University Belfast, Belfast, UK

\subsection{6/thoraxjn-2014-206260.384}

Introduction The fixed-dose combination (FDC) of tiotropium (T), a once-daily long-acting muscarinic antagonist, and olodaterol $(\mathrm{O})$, a once-daily long-acting $\beta_{2}$-agonist, is currently being evaluated in chronic obstructive pulmonary disease (COPD).

Two 52-week, Phase III replicate pivotal studies were conducted to assess the efficacy and safety of FDCs of T and $\mathrm{O}$ ( $\mathrm{T}$ $+\mathrm{O})$ delivered via Respimat ${ }^{\circledR}$ Soft Mist $^{\mathrm{TM}}$ inhaler in patients (pts) with GOLD Stage 2-4 COPD. Pooled safety data from the two studies are presented here.

Methods These were double-blind, randomised, parallel-group studies with 5 arms: O $5 \mu \mathrm{g}$, T $2.5 \mu \mathrm{g}$, T $5 \mu \mathrm{g}$, T+O 2.5/5 $\mu \mathrm{g}$, $\mathrm{T}+\mathrm{O} 5 / 5 \mu \mathrm{g}$. Key inclusion criteria were: age $\geq 40$ years, diagnosis of COPD, smoking history $>10$ pack-years. Pts with a history of asthma or significant disease other than COPD were excluded. Adverse events (AEs) were reported throughout the studies.

Results A total of 5162 pts were randomised and treated. In general, AEs, serious AEs and fatal AEs were balanced across treatment groups. In particular, frequencies of AEs in the cardiac disorders System Organ Class (SOC) and respiratory disorders SOC were similar.

\begin{tabular}{|c|c|c|c|c|c|}
\hline & \multicolumn{5}{|c|}{ Pts with $A E, \%$} \\
\hline & & & & $\mathrm{T}+0$ & $\mathrm{~T}+0$ \\
\hline & $05 \mu \mathrm{g}$ & Т $2.5 \mu \mathrm{g}$ & T $5 \mu \mathrm{g}$ & $2.5 / 5 \mu \mathrm{g}$ & $5 / 5 \mu \mathrm{g}$ \\
\hline & $\mathrm{n}=1038$ & $n=1032$ & $n=1033$ & $n=1030$ & $n=1029$ \\
\hline Total AEs & 76.6 & 73.4 & 73.3 & 74.7 & 74.0 \\
\hline Serious AEs & 17.4 & 15.1 & 16.7 & 16.3 & 16.4 \\
\hline Fatal AEs & 1.3 & 1.2 & 1.6 & 1.4 & 1.7 \\
\hline Cardiac disorders* & 5.7 & 5.8 & 5.3 & 5.8 & 4.5 \\
\hline \multicolumn{6}{|l|}{ Respiratory, } \\
\hline \multicolumn{6}{|l|}{ thoracic and } \\
\hline mediastinal disorders* & 45.3 & 43.9 & 42.7 & 38.2 & 39.4 \\
\hline
\end{tabular}

